\section{Lymphoepithelial carcinoma of the larynx: An unusual response to EXTREME regimen therapy. A new option for treatment?}

\author{
Daniele Bugada, ${ }^{1}$ Lucrezia Trozzi, ${ }^{2}$ \\ Davide Renna, ${ }^{3}$ Gerardo Petruzzi, ${ }^{4}$ \\ Barbara Pichi, ${ }^{4}$ Filippo Ricciardiello, ${ }^{5}$ \\ Consuelo D'Ambrosio, ${ }^{6}$ \\ Marco Bocchetti, ${ }^{7,8}$ Raul Pellini ${ }^{4}$
}

${ }^{1}$ Department of Ear, Nose, and Throat, Ear, Nose, and Throat Unit, University Hospital of Ferrara, Ferrara; ${ }^{2}$ Department of Otolaryngology-Head and Neck Surgery, Catholic University of Sacred Heart, Rome; ${ }^{3}$ Medical Oncology Unit, Sapienza Università di Roma, Rome; ${ }^{4}$ Department of Otolaryngology-Head and Neck Surgery, Regina Elena National Cancer Institute IRCCS, Rome; ${ }^{5}$ Ear, Nose, and Throat Unit, AORN “Antonio Cardarelli”, Naples; 'Division of Medical Oncology 1, Regina Elena National Cancer Institute, Rome; ${ }^{7}$ Department of Precision Medicine, University of Campania "Luigi Vanvitelli", Naples; ${ }^{8}$ Biogem Scarl, Molecular Oncology and Precision Medicine Laboratory, Ariano Irpino, Italy.

\section{Abstract}

Lymphoepithelial Carcinoma (LEC), an aggressive variant of Squamous Cell Carcinoma (SCC), is an undifferentiated carcinoma with an intermixed reactive lymphoplasmacytic infiltrate. Most cases of LEC occur in the nasopharynx, while it rarely involves other sites. LEC of larynx and hypopharynx is an extremely rare and aggressive neoplasm, characterized by a high propensity to loco-regional dissemination and a poor prognosis; it represents the $0,2 \%$ of all tumours of the larynx. Since it is such a rare tumor, the current literature provides only recommendations and there are no treatment guidelines available. A 70year-old man with laryngeal LEC and both distant and nodal metastases was treated with chemotherapy, following EXTREME regimen therapy. It was classified as a cT3 N3b M1 glottic cancer (Stage IVC, AJCC 8th Ed.), stage IVC. As the response on metastases was unexpectedly encouraging, surgical treatment on $\mathrm{T}$ could be performed. Patient underwent to total laryngectomy and bilateral neck dissection. To date, eight months after surgery, the patient is disease free. The unusual clinical course is reported.

\section{Introduction}

Lymphoepithelial Carcinoma (LEC) is a rare malignant tumor composed by undifferentiated and non-keratizing epithelial cells that possesses a characteristic nonneoplastic lymphoplasmacytic infiltrated stroma. ${ }^{1,2}$

LEC is significantly associated with Epstein-Barr Virus (EBV);-6 it shows an endemic distribution, reaching the greatest incidence in Southeast Asia. LEC most commonly affects the nasopharynx and very rarely involves anatomical sites other than Waldeyer's tonsillar ring. ${ }^{7-9}$ LEC of the larynx and hypopharynx represents $0.2 \%$ of all cancers of the larynx and is very aggressive, ${ }^{7,10}$ with loco-regional dissemination and lymph nodes metastases, that occur in $75 \%$ of cases. The prognosis is poor: fiveyear survival is estimated to be around $60 \%$ and patients show a median Overall Survival (OS) of less than 1 year. ${ }^{11-14}$ Alcohol and tobacco consumption do not seem to be risk factors for the development of LEC. Mean patient age is 62-years-old and male are more often affected than women (3:1 ratio is reported). ${ }^{14-16}$

As far as non-nasopharyngeal LEC is an extremely rare tumor, no treatment protocol is available nowadays: only small series or anecdotal cases can be found in English literature. ${ }^{17,18}$

LEC can hide in submucosal sites, which can delay and make diagnosis difficult. ${ }^{10,19,20}$ The biopsy must take a representative specimen in order to allow performing immunochemistry on the tissues, which is helpful in discovering the diagnosis, especially when the tumor is undifferentiated. ${ }^{21,22}$

From the histologic point of view, LEC presents non-neoplastic lymphocytes and plasma cells along with islands of malignant epithelial cells. ${ }^{23,24}$

Possible differential diagnoses include neuroendocrine carcinoma, alveolar and embryonal rhabdomyosarcoma, the most common types of non-Hodgkin's lymphoma, mucosal melanoma and laryngeal large cell neuroendocrine carcinoma. ${ }^{23,25,26}$

Radiotherapy appears to be the most appropriate conservative treatment for LEC, ${ }^{27-29}$ therefore, surgery is considered for locally advanced tumours. Ibrahimov et al. have recommended adjuvant chemotherapy for cases where surgery cannot be performed, but the effectiveness of chemotherapy on this tumor has yet to be demonstrated. $^{30}$
Correspondence: Gerardo Petruzzi, Department of Otolaryngology-Head and Neck Surgery, Regina Elena National Cancer Institute IRCCS, Via Elio Chianesi 53, 00144, Rome, Italy.

Fax: +0652665065

E-mail: petruzzigerardo@gmail.com

Key words: Lymphoepitelial carcinoma; larynx carcinoma; EXTREME regimen; head and neck.

Acknowledgments: We thank the patient for granting permission to publish this report

Conflicts of Interest: The authors declare no conflict of interest.

Availability of data and materials: All data underlying the findings are fully available.

Ethics approval and consent to participate: No ethical committee approval was required for this case report by the Department, because this article does not contain any studies with human participants or animals. Informed consent was obtained from the patient included in this study.

Consent for publication: The patient gave his written consent to use his personal data for the publication of this case report and any accompanying images.

Received for publication: 26 December 2020 Revision received: 2 March 2021.

Accepted for publication: 2 March 2021.

This work is licensed under a Creative Commons Attribution 4.0 License (by-nc 4.0).

(Copyright: the Author(s), 2021

Licensee PAGEPress, Italy

Translational Medicine Reports 2021; 5:9572 doi:10.4081/tmr.9572

\section{Case Report}

We report a case of a 70-years-old man first presented in August 2019, with a history of hoarseness and increasing neck lump. At flexible fibreoptic laryngoscopy, a submucous lesion involving the anterior third of both the vocal folds and the anterior commissure was identified. Mobility of the right vocal fold was affected. Respiratory space was preserved. The lesion did not involve the hypo glottis or dislocate the trachea. The remaining physical examination was negative.

MRI and PET were performed to stage the disease and to plan treatment. MRI showed the presence of a glottic neoformation extending to the anterior commissure 
and to both vocal cords anteriorly. Bilateral massive infiltration of the lower paraglottic space was reported, without infiltration of the thyroid cartilage. Several right lymph node levels in the neck appeared pathological.

A hypermetabolic neoplasm at the laryngeal level, lymph node metastases at the right laterocervical and mediastinal level, and also a hypermetabolic lytic alteration of the dorsal spine were found in PET images (Figure 1A).

In September 2019, incisional biopsy of the laryngeal lesion was performed under general anesthesia. Histopathologic study of all specimens demonstrated lymphoepithelioma of the larynx (Figure 2). Serological tests for antibodies specific for Epstein-Barr Virus (EBV) antigens were negative.

Considering the clinical staging of the tumour (Stage IVC: T3 N3b M1, AJCC $8^{\text {th }}$ Ed.), after multidisciplinary Disease Management Team (DMT) evaluation, the patient underwent systemic chemotherapy.

Consequently, patient was addressed to EXTREME regimen therapy (cisplatin, cetuximab and fluorouracil), ${ }^{31}$ recommended as the standard care for recurrent/metastatic head and neck cancer not eligible for surgery or chemotherapy with curative intent, accordingly to NCCN guidelines (2018). ${ }^{32}$ Vermoken et al. in 2008 demonstrated that survival can be significantly increased from 7.4 to 10.4 months by adding Cetuximab to 5-fluorouracil and cisplatin/carboplatin (the EXTREME regimen). ${ }^{33}$

In line with scheduled follow-up, 6 months from the first cycle of chemotherapy administration, PET-CT scan was performed: the patient was still alive with disease and showed an optimal response in terms of distant disease and lymph nodes while being stable in terms of the T stage of tumor cT3N0M0 (AJCC $8^{\text {th }}$ Ed) (Figure 1B).

Our patient showed a complete response of $\mathrm{M}$ and became eligible for surgery on $\mathrm{T}$ and $\mathrm{N}$, remaining disease-free at mid-term follow up.

Considering the improvement in the clinical picture, it was possible to perform a total laryngectomy with bilateral selective dissection of the neck.

Histopathological analysis confirmed laryngeal LEC, describing solid sheets or irregular islands of malignant epithelial cells with indistinct cell borders, round to oval vesicular nuclei, and a single and large central nucleoli. Solid pattern was intimately intermingled with prominent component of non-neoplastic lymphocytes and plasma cells.
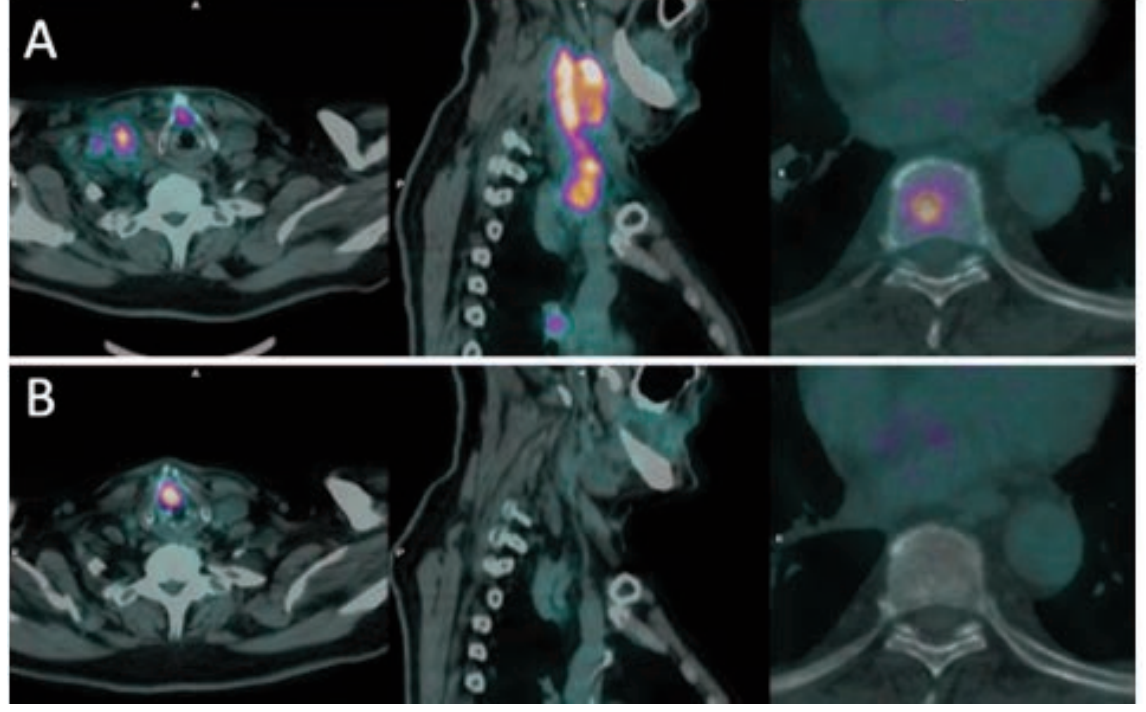

Figure 1. PET-CT scan: A) pre-treatment imaging; B) scan imaging post EXTREME therapy. The metabolic activity showed on bone and laterocervical lymph node, is absent after the EXTREME regimen. FDG is seen on Larynx.

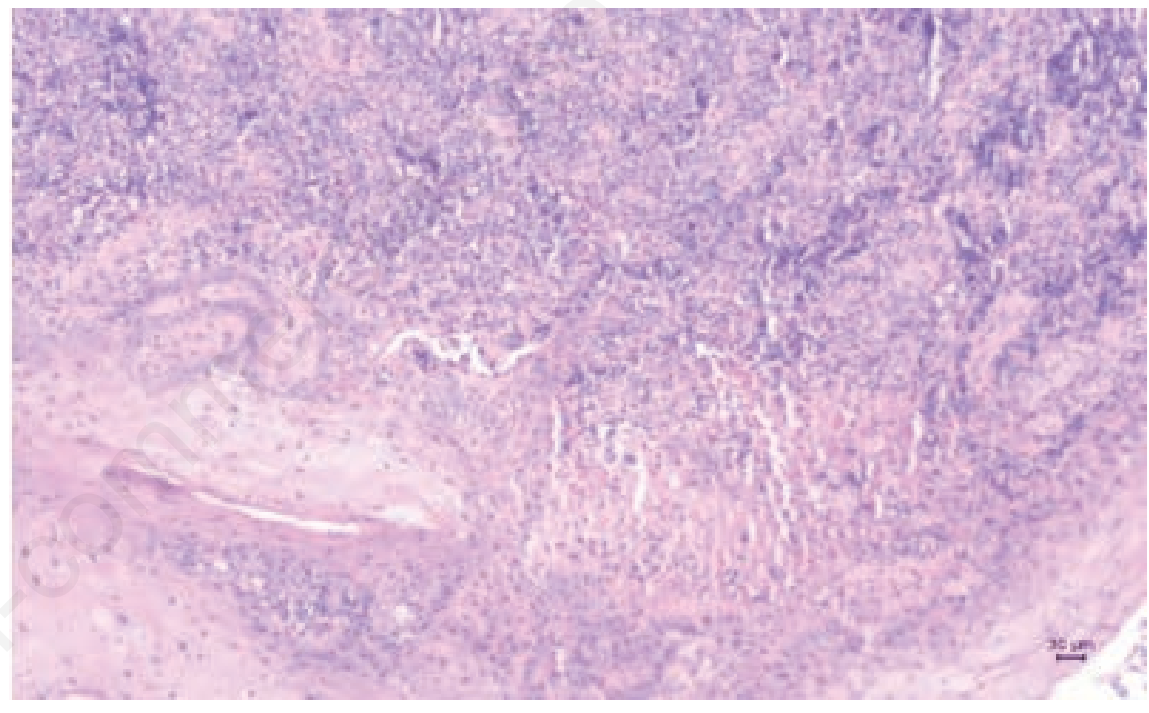

Figure 2. Hystologic specimen: hematoxylin and eosin staining, original magnification. Solid sheets or irregular islands of malignant epithelial cells with prominent component of non-neoplastic lymphocytes and plasma cells.

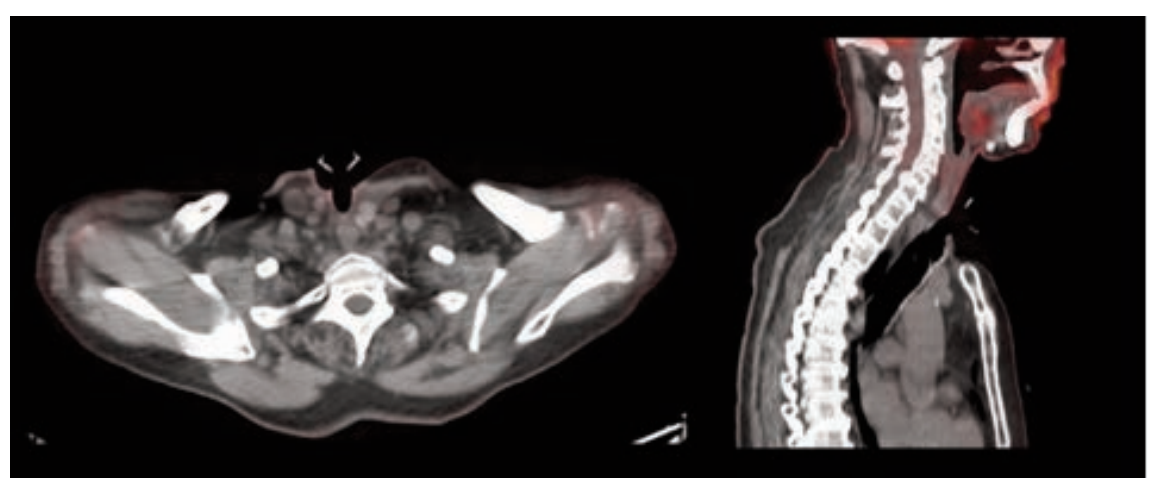

Figure 3. PET-CT at eight months follow up after surgical treatment. No evidence of disease (NED). 
The staging after histological examination was found to be $\mathrm{rpT} 3 \mathrm{pN} 0$ (AJCC $8^{\text {th }}$ Ed) with negative margins. According to NCCN 2020.1 guidelines, no adjuvant radiotherapy was performed. To date, eight months after surgery, the patient performed a PET-CT (October 2020), which was negative for persistence or recurrence of disease (Figure 3).

According to the EXTREME scheme, our patient received indication to continue treatment with Cetuximab as maintenance.

\section{Discussion}

At the present day, standardized chemotherapy protocols are not available for LEC treatment, a rare but aggressive neoplasm. ${ }^{34}$ Some studies suggest that LEC could be considered an "adverse feature": prognosis for LEC patients is poor compared to neoplasm equal for $\mathrm{T}$ and $\mathrm{N}$, in so far as five-year survival is estimated to be around $60 \%$ and the median overall survival is less than 1 year. ${ }^{11-13}$

It has been estimated that almost $87 \%$ of patients receive diagnosis of LEC already with local or lymph nodes metastases, so that are eligible for EXTREME regimen. ${ }^{35}$

The standard regimen is administered in line with the following therapeutic scheme: i) Cetuximab $400 \mathrm{mg} / \mathrm{mEq}$ on first administration and then $250 \mathrm{mg} / \mathrm{mEq}$ on days 1,8 and 15 and then repeat on day 21 ; ii) Cisplatin $100 \mathrm{mg} / \mathrm{mEq}$ in single administration and then repeat on day 21 (an alternative may be $20 \mathrm{mg} / \mathrm{mEq}$ for 5 consecutive days and then repeat on day 21); iii) Fluorouracil (5-FU) $200 \mathrm{mg} / \mathrm{mEq}$ on days 1 , 2, 3, 4, 5 and then repeat after 21 days.

Cisplatin dosage is modifiable, in consideration of the age, clinical condition and renal function of the patient. Another variant is the use of carboplatin instead of cisplatin, which has shown less renal toxicity and similar efficacy. ${ }^{33}$

On the other hand, for nasopharynx lymphoepithelial-like tumours, the EBVrelated cytotype, chemotherapy is indicated in addition to radiotherapy. ${ }^{36}$

As regard EBV theme, the EBV-LEC relationship have been proposed being crucial in lymphoepithelioma by virtue of an established association between EBV and nasopharyngeal carcinomas. However, the relationship between LEC that occur outside of the nasopharynx and EBV infection remains controversial.

Even though many question marks still remain, several researches are underway to improve the clinical outcomes of this kind of patient, looking for less toxic and equally effective treatment protocols.

\section{Conclusions}

In our institution we have recently treated an extremely rare case of lymphoepithelial carcinoma of the larynx. ${ }^{37-39}$ The patient had come to our attention at an advanced stage (stage IVC, AJCC $8^{\text {th }} \mathrm{Ed}$ ) so we opted for a chemotherapy-only treatment with EXTREME regimen, as suggested by the poor recommendations in the literature on lymphoepithelial carcinoma.

The unexpected effectiveness of this treatment on distant metastases allowed surgical treatment on the primary neoplasm and, after eight months, the patient is still alive free from disease.

To our knowledge, this is the first case of metastatic LEC to achieve such excellent results with chemotherapy treatment followed by surgery. ${ }^{40}$

In light of the surprising and remarkable response of metastases in our case to EXTREME treatment, we suggest considering it as induction chemotherapy and we recommend it in similar cases.

Further studies are needed to validate chemotherapy-regimen as a neoadjuvant therapy and assess its efficacy also in the management of LEC-like EBV-related nasopharynx tumours, ${ }^{41}$ even though the rarity of cases makes it harder to produce strong evidence. It still remains an interesting conundrum for research.

\section{References}

1. Andryk J, Freije JE, Schultz CJ, et al. Lymphoepithelioma of the larynx. Am J Otolaryngol 1996;17:61-3.

2. Ferlito A. Primary lymphoepithelial carcinoma of the hypopharynx. J Laryngol Otol 1977;91:361-7.

3. Svajdler M Jr, Kaspirkova J, Mezencev $\mathrm{R}$, et al. Human papillomavirus and Epstein-Barr virus in nasopharyngeal carcinoma in a non-endemic eastern European population. Neoplasma 2016;63:107-14.

4. Tardio JC, Cristobal E, Burgos F, Menarguez J. Absence of EBV genome in lymphoepithelioma-like carcinomas of the larynx. Histopathology 1997;30:126-8.

5. Kermani W, Belcadhi M, Sriha B, Abdelkéfi M. Epstein-Barr virus-associated lymphoepithelial carcinoma of the larynx. Eur Ann Otorhinolaryngol Head Neck Dis 2015;132:231-3.
6. Monteiro F, Baldaia H, Ribeiro L, et al. Epstein-Barr virus-associated with lymphoepithelial carcinoma: a rare tumor of the larynx. Clinical Med Insights: Ear Nose Throat 2019;12:1-4.

7. Bray F, Haugen M, Moger TA, et al. Age-incidence curves of nasopharyngeal carcinoma worldwide: bimodality in low-risk populations and aetiologic implications. Cancer Epidemiol Biomarkers Prev 2008;17:2356-65.

8. Jaipuria B, Dosemane D, Kamath PM, et al. Staging of Laryngeal and Hypopharyngeal Cancer: Computed Tomography versus Histopathology. Ir J Otorhinolaryngology 2018;30:189-94.

9. Ichikawa Y, Sumi M, Sasaki M, et al. Efficacy of diffusion-weighted imaging for the differentiation between lymphomas and carcinomas of the nasopharynx and oropharynx: Correlations of apparent diffusion coefficients and histologic features. AJNR Am J Neuroradiol 2012;33:761-6.

10. Nocini R, Molteni G, Mattiuzzi C, Lippi G. Updates on larynx cancer epidemiology. Chin J Cancer Res 2020;32:18-25.

11. Coskun BU, Cinar U, Sener BM, Dadas B. Lymphoepithelial carcinoma of the larynx. Auris Nasus Larynx 2005;32:189-93.

12. Toker C, Peterson DW. Lymphoepithelioma of the vocal cord. Arch Otolaryngol 1978;104:161-2.

13. Stanley RJ, Weiland LH, DeSanto LW, Neel HB. Lymphoepithelioma (undifferentiated carcinoma) of the laryngohypopharynx. 1985;95:1077-81.

14. WHO classification of tumor series. Available from: https://whobluebooks. iarc.fr/

15. Macmillan CA, Kapadia SB, Finkelswtein SD, et al. Lymphoepithelial carcinoma of the larynx and hypopharynx: study of eight cases with relationship to Epstein-Barr Virus and p53 gene alterations, and review of the literature. Hum Pathol 1996;27:1172-9.

16. Frank D, Cheron F, Cho $\mathrm{H}$, et al. Nonnasopharyngeal lymphoepitheliomas (undifferentiated carcinomas) of the upper aerodigestive tract. Ann Otol Rhinol Laryngol 1995;104:305-10.

17. Iocca O, Farcomeni A, Di Rocco A, et al. Locally advanced squamous cell carcinoma of the head and neck: A systematic review and Bayesian network metaanalysis of the currently available treatment options. Oral Oncol 2018;80:4051.

18. Narozny W, Betlejewski A, Stanklewicz 
C, Kaminski M. Ventriculosaccular lymphoepithelioma of the larynx: case report and literature review. Head Neck 1998;425-9.

19. Amin MB, Edge S, Greene F, et al (eds). AJCC Cancer Staging Manual, 8th Edition. Springer; 2017.

20. De Virgilio A, Costantino A, Mercante $\mathrm{G}$, et al. Transoral robotic surgery and intensity-modulated radiotherapy in the treatment of the oropharyngeal carcinoma: a systematic review and metaanalysis. Eur Arch Otorhinolaryngol. 2020 Jul 21. doi: 10.1007/s00405-02006224-z. Epub ahead of print.

21. Weiss LM, Gaffey MJ, Shibata D. Lymphoeptihelioma-like carcinoma and its relationship to the Epstein-Barr virus. Am J Clin Pathol 1991;96:156-8.

22. Zbaren P, Borisch B, Lang H, Greiner R. Undifferentiated carcinoma of nasopharyngeal type of the laryngopharyngeal region. Otolaryngol Head Neck Surg 1997;117:688-9.

23. Marioni G, Mariuzzi L, Gaio E, et al. Lymphoepithelial carcinoma of the larynx. Acta Otolaryngol 2002;122:42934.

24. Brandstorp-Boesen J, Falk RS, Evensen $\mathrm{JF}$, et al. Risk of recurrence in laryngeal cancer. PLoS One 2016;11:e0164068.

25. Dray T, Vargas H, Weidner N, Sofferman RA. Lymphoepitheliomas of the laryngohypopharynx. Am J Otolaryng 1998;19:263-6.

26. Hammas N, Benmansour N, El Alami El Amine M, et al. Lymphoepithelial carcinoma: a case report of a rare tumor of the larynx. BMC Clinical Pathology 2017;17:24

27. Steuer CE, El-Deiry M, Parks JR, et al. An update on larynx cancer. CA Cancer J Clin 2017;67:31-50.

28. Regaud C. Lympho-epitheliome de l'hypopharynx traité par la roentgenthérapie. Bull Soc Franc Otorhinolaryngol 1921;34:209-14.

29. Schmincke A. Über lymphoepitheliale Geschwülste. Beitr Pathol Anat 1921;68:161-70.

30. Ibrahimov M, Yilmaz M, Celal MH, et al. Lymphoepithelial carcinoma of the larynx. J Craniofac Surg 2013;24:1049.

31. Sano D, Fujisawa T, Tokuhisa M, Shimizu M. Real-world treatment outcomes of the EXTREME regimen as first-line therapy for recurrent/metastatic squamous cell carcinoma of the head and neck: a multi-center retrospective cohort study in Japan. Anticancer Res 2019;39:6819-27.

32. Colevas AD, Yom SS, Pfister DG, et al. NCCN guidelines insights: head and neck cancers, version 1.2018. J National Comprehensive Cancer Network 2018;16:479-90.

33. Vermoken J, Mesia R, Rivera F, Remenar E. Platinum-based chemotherapy plus Cetuximab in head and neck cancer. N Engl J Med 2008;359;11.

34. Becker M, Moulin G, Kurt AM, et al. Atypical squamous cell carcinoma of the larynx and hypopharynx: radiologic features and pathologic correlation. Eur
Radiol 1998;8:1541-51.

35. Tan E, Mody MD, Saba NF. Systemic therapy in non-conventional cancers of the larynx. Oral Oncology 2018;82:618.

36. De Virgilio A, Costantino A, Mercante G, et al. Present and Future of De-intensification Strategies in the Treatment of Oropharyngeal Carcinoma. Curr Oncol Rep 2020;22:91.

37. Dubey P, Ha CS, Ang KK, et al. Nonnasopharyngeal Lymphoepithelioma of the Head and Neck. Cancer 1998;82:1556-62.

38. Sone M, Nakashima T, Nagasaka T, et al. Lymphoepithelioma-like carcinoma of the larynx associated with an Epstein-Barr viral infection. Otolaryngol Head Neck Surg 1998;119: 134-7.

39. Torabi SJ, Cheraghlou S, Kasle DA, Savoca EL, Judson BL. Nonsquamous cell laryngeal cancers: incidence, demographics, care patterns, and effect of surgery. Laryngoscope 2019;129:24962505.

40. Nachalon Y, Cohen O, Alkan U, Shvero J, Popovtzer A. Characteristics and outcome of laryngeal squamous cell carcinoma in young adults. Oncol Lett 2017;13:1393-7.

41. Chan JYK, Wong EWY, Ng SK, Vlantis AC. Nonnasopharyngeal head and neck lymphoepithelioma-like carcinoma in the United States: a population-based study. Head Neck 2016;38:E1294-300. 